\title{
Application of Lean Manufacturing Tools in the Food and Beverage Industries
}

\author{
Rui Borges Lopes ${ }^{1 *}$, Filipa Freitas ${ }^{2}$, Inês Sousa ${ }^{3}$
}

\begin{abstract}
Recent years have shown an increasing use of lean manufacturing (LM) principles and tools in several industrial sectors. Already a wellestablished management philosophy, it has shown numerous successful applications even outside production environments. This work presents the application of some LM tools, and the corresponding shift in philosophy, in two Portuguese companies of the food and beverage industries. Main implementation issues are presented and discussed; followed by the results obtained from the application of LM tools in the production system of these companies. Significant gains are obtained in both companies and, more importantly, it instills a continuous improvement culture and increases production flexibility while reducing lead times.
\end{abstract}

Keywords: lean manufacturing; food and beverage industries; process innovation; case studies.

Submitted June 29th 2015 / Approved October 7th 2015

\section{Introduction}

As innovation is one of the critical success factors for productivity (Utterback \& Abernathy, 1975) process innovation initiatives have been sought and undertaken by companies as means of staying competitive or ahead of the competition. Process innovation can be defined as the implementation of new or significantly improved production or delivery method, including significant changes in techniques, equipment and/or software (OECD, 2005, p. 49). It intends decreasing logistics or production costs, increase quality, or produce/deliver new or significantly improved products (OECD, 2005, p. 49).

Companies that do not institute continuous improvement after implementing process innovation are likely to revert to old practices (Davenport, 1993, p. 25). Lean manufacturing (LM) has shown to be a good example of process innovation in companies, having continuous improvement as one of its cornerstone.

LM intends reducing waste in human effort, inventory, time to market and manufacturing space to become highly responsive to customer demand, while delivering quality products efficiently (Womack et al., 1990). Originating from the automotive industry, LM has now been applied in several other sectors and even extended beyond production environments, showing impressive gains (Womack et al., 1990; George, 2003; Holden, 2011). A recent review on LM is by Marodin and Saurin (2013) which shows a steady increase in publications, where nearly half of the works concern companies located in USA or UK. Most studies were from the manufacturing (unspecified), service, automotive and electronic components sectors. For the case of the food industry only 3 works were found, which is in line with the findings by Dora et al. (2014) that show a generally low implementation of LM practices in the food industry.
Despite the success record, lean practices have also brought about some risks. For example, in managing lean supply chains the reduction in inventories has created high vulnerability to turbulences (Thun \& Hoenig, 2011) - also in the case of food-related industries (Vlajic et al., 2012). This mixed success has mostly been noticed outside of the production environment. Looking at a specific case, the red meat production and supply, Cox and Chicksand (2005) found that the inter-organisational aspects of lean (concerning supply) were neither easily applicable nor appropriate for most participants. The same authors however, point out that internal adoption of lean practices were found appropriate for all participants. This can also be concluded looking at the work by Simons and Zokaei (2005), showing that these practices may have interesting benefits in food-related production systems.

So, the main question arising at this point is: why is the food industry so unique concerning implementation of LM practices and why is it so behind the remaining sectors?

Concerning uniqueness of the sector, Dudbridge (2011) puts forward three main reasons: (1) political reasons, the supply of safe affordable and plentiful food is critical to nations, making this sector highly regulated; (2) food business, huge quantities of food have to be shipped every day, making reliability of supply chains critical and availability of products and price competitiveness paramount for success; (3) food fashion, consumers are constantly tempted to try new products, making companies launch new products regularly and consequently increasing complexity in production.

Regarding implementation, LM is seen as not easily applicable to industries with large batch processes such as the food and beverage industries. Companies sell their products from large distribution cen-

1 Department of Economics, Management and Industrial Engineering / CIDMA, University of Aveiro, Portugal.

2, 3 Department of Economics, Management and Industrial Engineering, University of Aveiro, Portugal.

${ }^{*}$ Corresponding author: rui.borges@ua.pt 
tres and manufacture according to a forecast. Lack of leadership, vision and employee involvement are also identified (Heymans, 2015, p. 1). Additional barriers in the implementation of LM practices are identified by Dora et al. (2014) which result from the special characteristics of the food sector. The authors summarize these characteristics, emphasizing highly perishability of products, complicated processing, extremely variable raw materials, recipes and unpredictable demand.

According to Mahalik and Nambiar (2010, p. 123), increased regulations in the food and beverage industries have resulted in many cases to increased costs, requiring process improvements and innovations in other areas for reducing costs. The authors stress the need for employing LM tools, hinting that often the packaging machinery is severely under-utilized, possibly due to shorter production runs and frequent changeovers. Other authors (Boston Consulting Group, 2015; Heymans, 2015) have also advocated the need to implement lean principles in the food industry for aiming staying competitive, stating that LM remains an underused approach.

Heymans (2015) encourages embracing this philosophy for simplifying processes, increasing percentage of value-adding activities and improving operational performance. Effective application of LM principles and tools would significantly reduce non-value added time, waste and associated costs, therefore improving customer service and obtaining higher satisfaction levels. Moreover, benefits may extend beyond the addressed processes, instilling a continuous improvement culture in organizations.

To help fill the gap in the literature and possibly benefit practitioners, this work presents two case studies of implementation of lean principles and tools in the production system of companies from the food and beverage industries. The remainder of this paper is structured as follows. In the second section, for the used LM tools a literature review and introduction are presented. Afterwards, the methodology adopted for the two case studies will be detailed, with implementation aspects and results presented and discussed. Finally, conclusions are drawn in the last section.

\section{Literature review}

Not all companies can/should implement the same set of practices. Generally, the success of any management practice depends on organizational characteristics (Sousa \& Voss, 2008). Likewise, implementing lean is not straightforward, if not properly planned it will raise many obstacles, such as (Hodge et al., 2011): resistance to change; reluctance in contributing with suggestions for improvement; lack of motivation; and lack of knowledge of the lean philosophy and its tools.

Initial implementation stages typically involve an initial value stream mapping (VSM) for starting changing mentalities and raising awareness to the advantages of lean. Afterwards, production environments must be organized using $5 \mathrm{~S}$. Then, following a continuous improvement culture, major issues are identified, for which the most appropriate tools are employed (Pearce \& Pons, 2013).
In the two case studies detailed in this work, companies were at different implementation stages. In the first case, lean concepts had been recently introduced and workspaces were generally poorly organized. This led to several non-value adding activities (e.g. searching for specific tools, lack of cleanliness, etc.) which had to be addressed; $5 \mathrm{~S}$ methodology was employed. Then, at a later stage, the main identified issue was changeover times. This problem was also found in the second case study, due to the previously identified characteristics of the food and beverage industries. For addressing this, single-minute exchange of die (SMED) was applied.

Both 5S and SMED lean tools will be presented and reviewed as follows.

\section{S methodology}

The acronym $5 \mathrm{~S}$ derives from five Japanese words which begin with the letter S: seiri, seiton, seiso, seiketsu and shitsuke. These correspond to the five steps of the $5 \mathrm{~S}$ methodology including sort, set in order or place, shine or scrub, standardise, and sustain. It is a workspace organization method, applicable to any type of business or operation, being a vital component of visual management (Hirano, 1996).

The 5S methodology aims maintaining workplaces in excellent condition through their storage, organization and cleanliness (Courtois et al., 2007). It is a tool used to instil continuous improvement in a gradual and sequential way which, with little effort and cost, allows organisations to satisfy various international standards (Bayo-Moriones et al., 2010). Although a simple system, implementation in practice may not be an easy task, given that its success highly depends on acceptance from employees, modification of their habits and attitudes, and involvement and commitment of the top management (Dennis, 2007).

Successful application of $5 \mathrm{~S}$ may provide the following advantages (Chapman, 2005; Kumar et al., 2006; Gapp et al., 2008): workplaces more efficient, organized, clean, productive and safe; improvement of working conditions and values of the employees; better view of the problems; embodiment of daily activities by employees; increased productivity, flexibility, quality, safety and motivation of employees; reduction of costs, unproductive time, space and movements; and reduction of losses related with failures and breaks.

The five steps of $5 \mathrm{~S}$ are now introduced, with an overview provided in Figure 1.

Seiri - Sort. The first step consists in selecting only the objects and documents that are required for the process. It is therefore needed to identify and classify all objects/documents that are in the workplace. Tools, materials and documents necessary for the workspace' processes will be kept, the remaining may be stored in other locations or even removed altogether (Kumar et al., 2006).

Seiton - Set in order. After identifying the items to be kept in the workplace it is necessary to organize them and store them in suitable 
places. At this stage rules must be set, identifying the storage places and ensuring items are placed in their respective places. This allows materials and documents to be located and stored as quickly as possible (Courtois et al., 2007).

Seiso - Shine. This step can be performed in parallel with the organization and storage phase. It aims ensuring that workplaces and machines are cleaned regularly and are in optimal operating conditions, as anomalies are usually detected more quickly and easily in cleaner workplaces (Courtois et al., 2007).

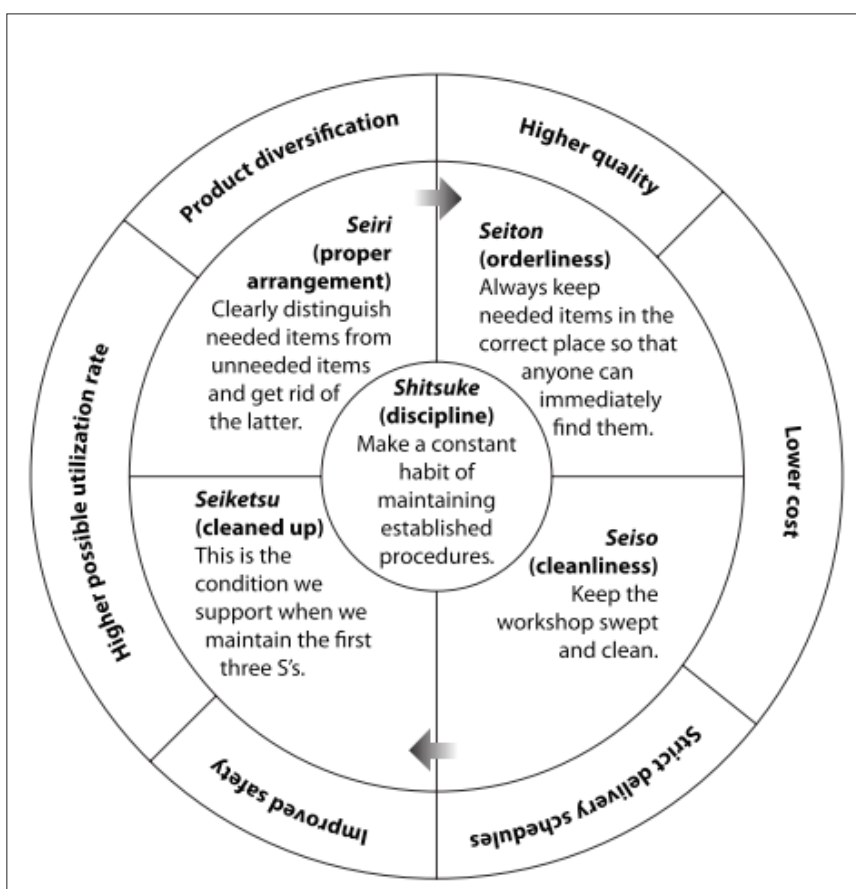

Figure 1. Overview of the 5S steps (Hirano, 2009, p. 250).

Seiketsu - Standardize. After performing the previous steps it is possible to say that the company has reached an optimal state, given that workplaces are clean, organized and good looking. However, when achieving this step it also faces the most complicated aspect of 5S: trying to keep workplaces in excellent conditions in the long term. To accomplish this, companies must standardize rules defined in the previous steps, which should be done together with employees as they are the most knowledgeable of their workplaces, equipment and most frequent problems/anomalies. This step should ensure that all rules are followed so that organization, storage and regular cleaning become a habit, preventing the return of previous bad habits (Patel \& Thakkar, 2014).
Shitsuke - Sustain. The last step of 5S aims checking if materials and documents are stored in the suitable places, inspections are performed, equipment are in normal operating conditions and regular cleaning is being performed (Patel \& Thakkar, 2014). At this stage companies must effectively promote $5 \mathrm{~S}$, train their employees about all aspects of the methodology and ensure they meet their responsibilities.

\section{SMED}

Developed by Shingo (1985), single-minute exchange of die (SMED) is an LM methodology which aims to systematically reduce changeover times, ideally to single-digit minutes. Changeover time is the period between two good products coming out of a machine where the second product is from a different production order (Gest et al., 1995) - activities performed during this time are usually non-value adding.

Rapid changeover is critical for reducing lot sizes and therefore improving flow and production flexibility. These are key aspects in businesses as it measures efficiency and competitiveness and is an effective way to lower costs, being the main benefits of SMED (Mika, 2006; Coimbra, 2009).

Changeover can be divided into three main periods (Mika, 2006; Henry, 2012): (1) run-down or clean-up, removal of material remaining from previous production and cleaning; (2) setup, physically converting machines to enable producing new products; and (3) run-up or start-up, when steady state manufacture is being re-established, meeting required productivity and quality rates, usually including adjustments and quality checking.

Originally focused on setup times, SMED has been extended over the years with a set of leveraging tools (McIntosh et al., 2007) and in order to address all three main periods within changeover (Ferradás \& Salonitis, 2013). Also, instead of focusing solely on organizational based improvements, manufacturing equipment design improvements have also been considered (Cakmakci, 2008). The number of successful SMED implementations has been extensive (e.g. Moreira \& Pais, 2011; Ferradás \& Salonitis, 2013); however, the only work found specifically addressing applications in the food and beverage industries is by Kennedy et al. (2013).

The three main stages of the SMED methodology, following Shingo (1985), are detailed as follows and depicted in Figure 2. To ensure successful implementations, other aspects are also required considering (Ferradás \& Salonitis, 2013): choosing the appropriate team; definition of achievable targets; and the type of industry and equipment to employ the methodology. 


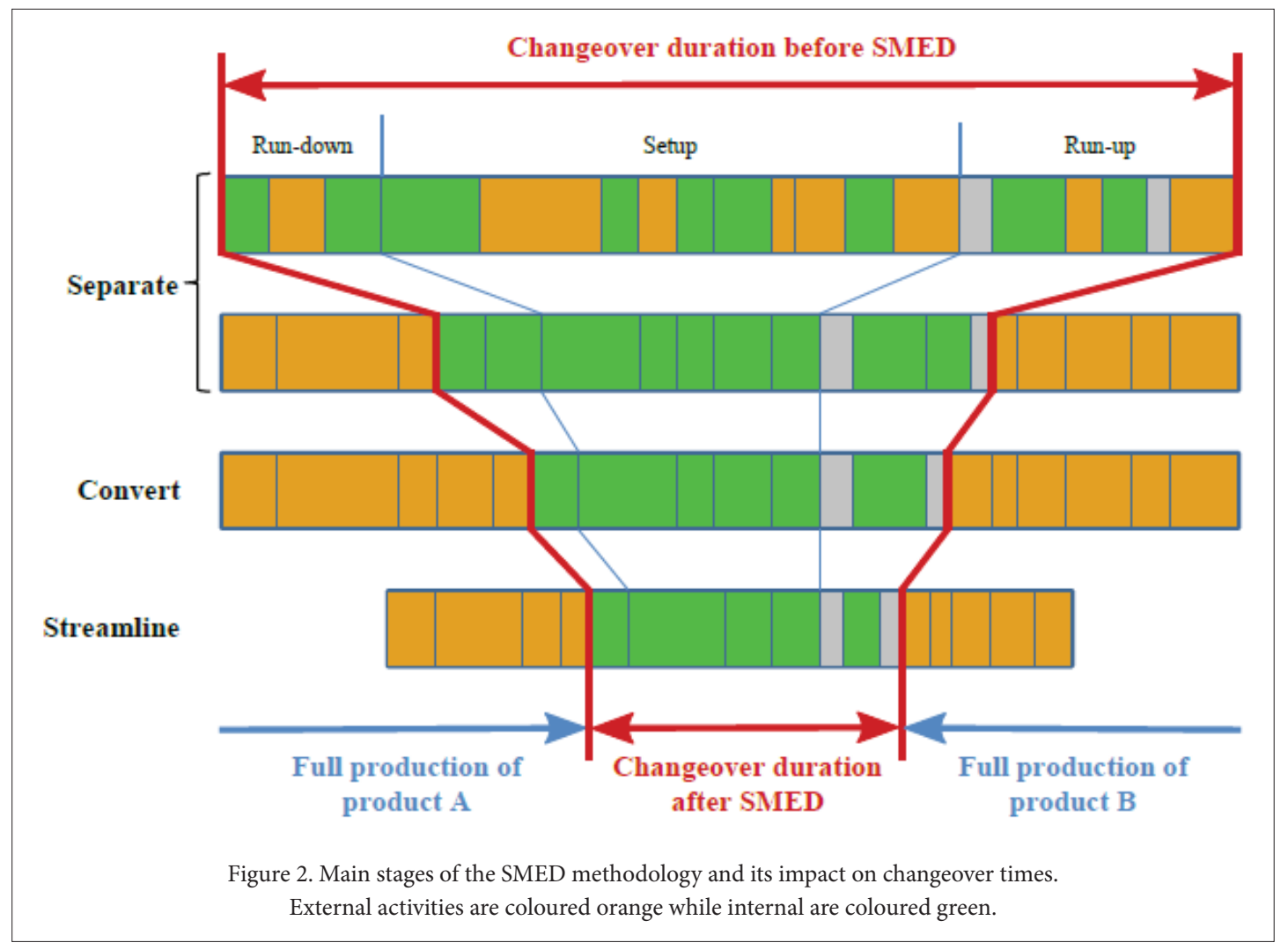

Separate. Initially, all activities have to be classified as external or internal based on whether they can be performed, respectively, while the machine is working or not. These can be categorized using video recordings and routing diagrams (Ferradás \& Salonitis, 2013). This is usually the most important step in the implementation of SMED, since many activities can be performed with the machine working and frequently are not, as operators wait for the machine to stop in order preform them (Shingo, 1985). Afterwards, both sets of tasks are separated. Often it is also useful to distinguish between run-down, setup and run-up periods (Ferradás \& Salonitis, 2013).

Convert. In this stage, two major tasks are to be performed. Firstly, a thorough analysis of previously classified internal activities is to be done for detecting wrong assumptions; then, internal activities must be attempted converted into external, using organizational or equipment design improvements. Shingo (1985) proposes several techniques to support this stage, such as tool standardization and use of intermediary jigs.

Streamline. Finally, all aspects of the changeover operation must be streamlined and simplified. This last stage encompasses systematic improvement of all operations by reduction and elimination. Internal activities should be given priority although not neglecting external. Ways to address this is by implementing parallel operations, increasing mechanization, reducing adjustments and using more efficient tools (Shingo, 1985). Benefits of each proposal must be carefully evaluated to ensure most time-improving and cost-efficient measures are employed (Ferradás \& Salonitis, 2013).

\section{Research methodology}

Process innovations in two companies of the food and beverage industries are reported as follows. Main objectives of the companies were taken into account in the development of the case studies, which were prepared following a qualitative approach (Yin, 2014). The case studies concern two Portuguese companies, whose names will be dissimulated for confidentiality reasons, and occurred during 20132015. Both companies intended reducing batch sizes and implement a continuous improvement culture, which triggered the need for process innovation.

Company A is a medium-sized company with around 250 employees and a sales volume of 25 million Euros in 2014. The company produces beer and other alcoholic and non-alcoholic beverages with distribution nationwide. It produces not only its own brands but also worldwide-known beverages for the Portuguese market having recently started its internationalization process. Additionally, the company handles distribution and acts as representative of several other well-known brands. In its production facility the company has 6 bottling lines: two are for glass bottles, three are for filling PET bottles and one filling line is dedicated to kegs. The case study was conducted in one of the glass bottles filling lines were 5S and SMED were applied. As the company was making its first steps in the lean journey, this was to be the testing grounds for possible company-wide adoption of lean principles and tools. 
Company B is part of a major leading group in the Portuguese food industry. The group had a sales volume of 200 million Euros in 2014 and around 650 employees in five major production centres. The company produces mostly for the Portuguese market with its own brands - well-known and highly regarded in Portugal. The group also produces and owns other brands directed at international markets. The production centre where the case study took place is the biggest of its kind in the Iberian Peninsula and handles packaging of several varieties of pasta in a total of 9 packaging lines. The case study was specific to lines 1-5, the remaining being scheduled for SMED implementation at a later stage. In this case lean principles were already known to company employees, however, past failed SMED implementations caused overall mistrust concerning lean.

For both case studies the approach to process innovation as proposed by Davenport (1993) was chosen; an overview can be seen in Figure 3. Processes candidate for innovation were identified based on their impact on productivity and the hindrance they caused on future company strategies (namely, having more flexible production systems for making smaller batches). Identified change enablers were the LM management philosophy and its tools, and the companies' employees. Afterwards, main objectives were defined for the processes being addressed. The last two steps are more thoroughly detailed in the following subsections, focusing on understanding current processes and using lean tools for helping designing new processes.

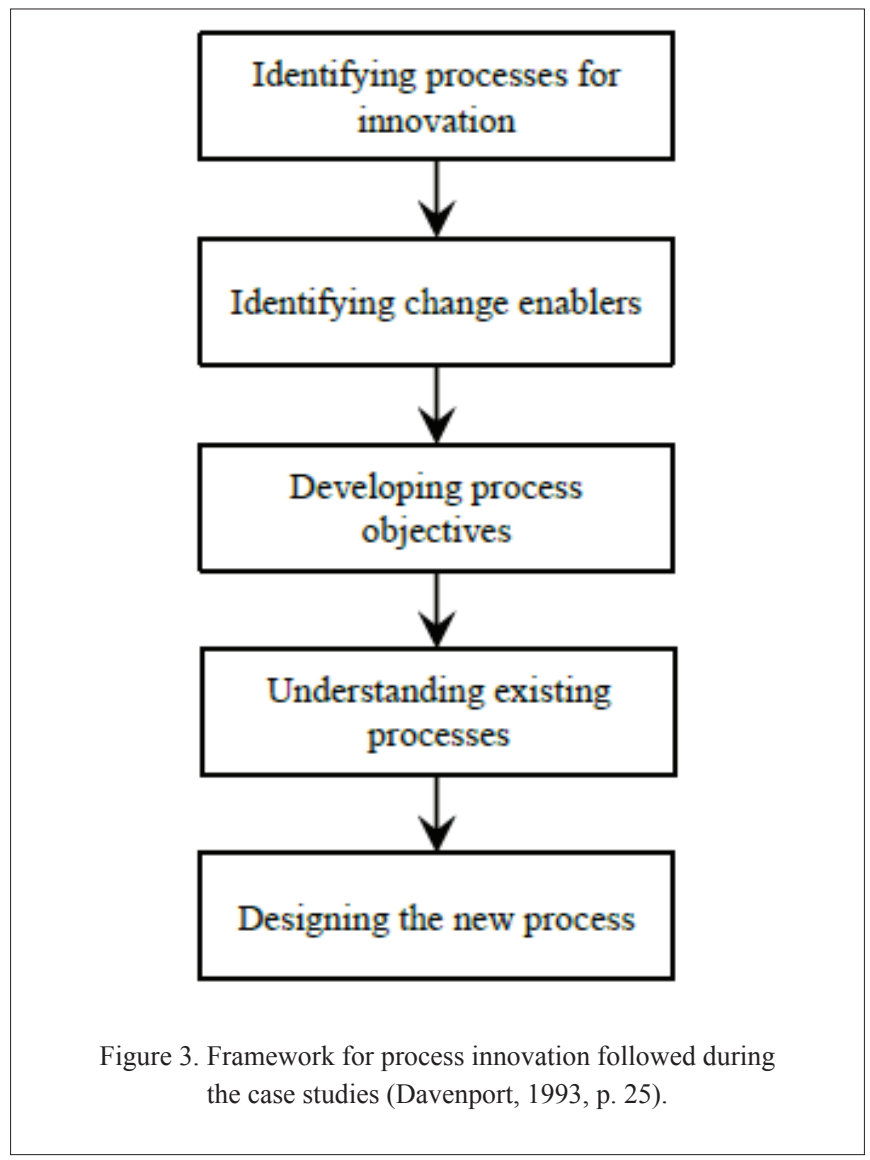

\section{Case study: Company A, application of 5 S and SMED}

This case study concerns one of the glass bottles filling lines of Company A. The line fills: beer bottles of $20 \mathrm{cl}, 25 \mathrm{cl}$ and $30 \mathrm{cl}$; juice bottles of 33cl; and carbonated and soda water bottles of $33 \mathrm{cl}$. For each of these, several different flavours and brands are produced. A total of 14 machines are operating in the line.

For the implementation of the lean tools, firstly, employees were sensitized on the importance of the project, the lean concepts, and the main objective of the implementations that were about to occur. Then, they were informed and trained on the methods that were to be employed (5S and SMED) and motivated to achieve successful applications. Methodology and results are reported as follows.

\section{Application of 5S}

The 5S methodology was applied on several workstations in the previously mentioned filling line. Firstly, a detailed analysis was made on each of the workstations, evaluating organization of equipment and which tools and documents were needed to perform most common operations.

Main identified issues were materials disorganized, equipment parts on the floor, lack of identification of storage places, equipment sharing between workstations and excess of materials (some examples can be seen on Table 1, left-hand column). These issues were affecting productivity and were in some cases serious health risks: broken glass bottles, metal bottle caps and lighters could be found in storage boxes. Cleanliness was also a problem, being noticed the lack of inspection norms in the workspaces and general dirtiness of some storage places, parts and of the floor.

After the analysis on the current status of the shop floor, an evaluation checklist was produced for each workstation with the main issues requiring addressing in each of the $5 \mathrm{~S}$ steps. The checklist template can be seen in Table 2, which had column "observations" filled at this stage. In a brainstorm session with the team, the evaluation checklist was analysed and corrective measures were proposed to solve the issues.

Finally, corrective measures were implemented, consisting in tidying up, organizing, cleaning, normalizing and establishing control measures in workstations. Afterwards, the evaluation checklist of Table 2 was performed again and was set as a routine task to instil a continuous improvement environment and for ensuring the last $5 \mathrm{~S}$ step: sustain. 


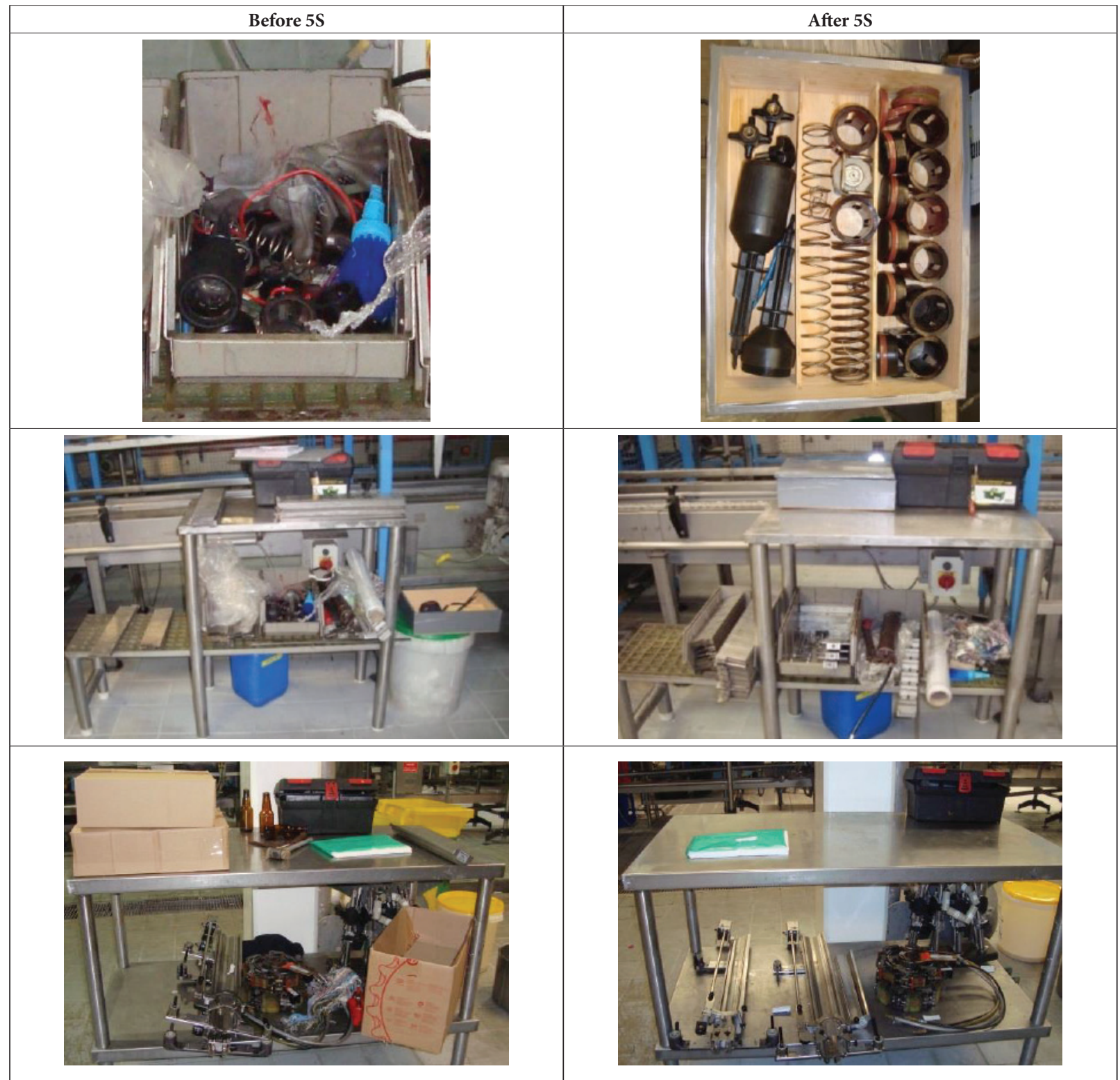

Table 1. Some examples of workspaces before and after $5 \mathrm{~S}$ implementation.

Although benefits of this methodology are not easily measurable, the following advantages were identified:

- less risk of work accidents

- better working conditions

- employees more engaged and with an overall better working attitude

- organized workstations

- optimized storage space

- less movements from employees

- reduction of unproductive times.

Furthermore, current state of workstations was found extremely helpful in identifying problems and potentiate further improvements in the filling line, being considered invaluable upon the application of SMED, which ensued. 


\begin{tabular}{|c|c|c|c|c|}
\hline & $\mathrm{Nr}$ & Evaluation criteria & Observations & Corrective measures \\
\hline \multirow{5}{*}{ 1S } & 1.1 & Obsolete materials in the workstation (WS)? & & \\
\hline & 1.2 & Unused or obsolete equipment in WS? & & \\
\hline & 1.3. & Unnecessary transportation or storage materials in WS? & & \\
\hline & 1.4 & Unnecessary elements in WS? & & \\
\hline & 1.5 & Unnecessary information in WS? & & \\
\hline \multirow{2}{*}{$2 S$} & 2.1 & WS identified and according to defined standards? & & \\
\hline & 2.2 & Distinctive markings in WS and according to standards? & & \\
\hline \multirow{3}{*}{$3 S$} & 3.1 & WS, equipment, transportation and storage material clean? & & \\
\hline & 3.2 & Cleaning schedules or checklist defined? & & \\
\hline & 3.3 & Necessary cleaning materials available in WS? & & \\
\hline \multirow{3}{*}{$4 \mathrm{~S}$} & 4.1 & Objects stored in the correct place? & & \\
\hline & 4.2 & Standards defined and being followed? & & \\
\hline & 4.3 & Checklists for correct handling of equipment being followed? & & \\
\hline \multirow{2}{*}{$5 S$} & 5.1 & Standards in $4 \mathrm{~S}$ implemented and continuously improving? & & \\
\hline & 5.2 & Norms defined in previous topics being followed? & & \\
\hline
\end{tabular}

Table 2. Evaluation checklist for each workstation before and after $5 \mathrm{~S}$ implementation.

\section{Application of SMED}

One of the most important processes identified for innovation was the tool changeover occurring in the filling line. Machines operating the line had, on average, 15 changeovers/month, each taking significant times. This had to be addressed for increasing productivity and flexibility, and reducing delivery times. Out of all the machines three were identified as critical: blowing machine, bottle packing machine, and labelling machine. For designing new changeover processes for these three machines SMED was implemented, following the stages as proposed by Shingo (1985).

Before the first stage of SMED a thorough analysis of the production system was conducted. This was important to truly understand the changeover operations and identify possible problems in the process. This was done by direct observation of all the operations performed (even outside changeover periods) and in constant dialog with the workers usually operating the machines and performing changeovers - note that there was no historical data on the company concerning changeovers. Dialoguing with the production engineering staff and the head of production was also critical to access the validity of collected data. Information collected was: required operations, corresponding sequence and time to perform them; main problems encountered in changeovers; and identification of issues affecting productivity and their causes.

The first issue that was uncovered was that each operator had its own way of performing the changeover: the one (s)he felt was the most correct and fastest. This made necessary collecting data of different operators for the same changeover. Also, it could be seen that operators only started changeover activities after machines had stopped. Other issues encountered in this previous analysis were:

- lack of standards or documents explaining how changeovers should occur

- lack of training of operators

- variability in operations sequence and work methods during changeover

- few operators and no one was assigned to coordinate the changeover

- lack of adequate tools

- difficulty in performing equipment calibration and adjustments.

Changeovers would generally take similar times and have same tasks regardless of the products ending and starting production. Number of tasks performed and corresponding average times can be seen in Table 3 grouped according to run-down, setup and run-up periods.

\begin{tabular}{|l|c|c|c|c|c|c|}
\cline { 2 - 7 } \multicolumn{1}{c|}{} & \multicolumn{2}{c|}{ Blowing } & \multicolumn{2}{c|}{ Bottle packing } & \multicolumn{2}{c|}{ Labelling } \\
\cline { 2 - 7 } \multicolumn{1}{c|}{} & \# Tasks & Time & \# Tasks & Time & \# Tasks & Time \\
\hline Run-down & 3 & $00: 06: 00$ & 2 & $00: 00: 12$ & 4 & $00: 06: 01$ \\
\hline Setup & 22 & $01: 01: 09$ & 11 & $00: 15: 46$ & 22 & $00: 23: 55$ \\
\hline Run-up & 5 & $00: 18: 50$ & 9 & $01: 03: 58$ & 13 & $00: 42: 42$ \\
\hline Total & $\mathbf{3 0}$ & $\mathbf{0 1 : 2 5 : 5 9}$ & $\mathbf{2 2}$ & $\mathbf{0 1 : 1 9 : 5 6}$ & $\mathbf{3 9}$ & $\mathbf{0 1 : 1 2 : 3 8}$ \\
\hline
\end{tabular}

Table 3. Number of tasks and average changeover times before SMED for each machine. 
In the "separate" stage all tasks were classified as internal or external and grouped accordingly as proposed by the methodology. Then followed the "convert" stage, where 6, 4 and 8 tasks, respectively from the blowing, bottle packing and labelling machines were converted into external. These tasks mostly concerned die preparation, fetching/ storing materials for performing the changeover, and lubricating and cleaning machine parts; all of which could be done while machines were operating. Finally, in "streamline", all tasks were analysed to check for possible improvements. Performing tasks in parallel, easy to use clamp screws, and dedicated movable workbenches were some of the changes implemented, none requiring additional operators. All tasks were also considered necessary for the respective changeover.

Data concerning changeovers after SMED implementation can be seen in Table 4, where the last line shows the gains achieved in each of the machines. Improvements for the blowing and labelling machines were respectively around $21 \%$ and $37 \%$. In the bottle packing machine no relevant improvements were achieved. This was mostly because most time consuming tasks concerned calibration and adjustments in the machine (run-up period), which could not be reduced for ensuring quality.

\begin{tabular}{|l|c|c|c|c|c|c|}
\cline { 2 - 7 } \multicolumn{1}{c|}{} & \multicolumn{2}{c|}{ Blowing } & \multicolumn{2}{c|}{ Bottle packing } & \multicolumn{2}{c|}{ Labelling } \\
\cline { 2 - 7 } \multicolumn{1}{c|}{} & \# Tasks & Time & \# Tasks & Time & \# Tasks & Time \\
\hline External & 6 & $00: 08: 57$ & 4 & $00: 01: 09$ & 2 & $00: 25: 01$ \\
\hline Run-down & 0 & $00: 00: 00$ & 1 & $00: 00: 07$ & $00: 00: 57$ \\
\hline Setup & 21 & $00: 57: 14$ & 8 & $00: 14: 42$ & 22 & $00: 22: 58$ \\
\hline Run-up & 3 & $00: 10: 30$ & 9 & $01: 03: 58$ & 7 & $00: 21: 47$ \\
\hline Total internal & 24 & $01: 07: 44$ & 18 & $1.44 \%$ & 31 & $00: 45: 42$ \\
\hline Improvement & & $21.23 \%$ & & & $37.08 \%$ \\
\hline
\end{tabular}

Table 4. Number of tasks and average changeover times after SMED for each machine and separated according to external or internal (run-down, setup, and run-up).

Reduction of changeover times was achieved with organizational based improvements, allowing gains in productivity with negligible investment. Moreover, it allowed: standardizing work methods for the changeovers, introducing visual management, keeping storage areas more organized, and made employees more engaged and searching for ways to improve the production system. Savings in manufacturing costs were estimated to amount to 35.000 Euros/year just from reducing changeovers times.

It is worth noting that this was one of the first steps in the lean journey by the company. In a continuous improvement philosophy and with additional lean experience the company may further improve changeover times, possibly by attempting equipment design improvements.

\section{Case study: Company B, application of SMED}

The second case study concerns the application of SMED in Company $\mathrm{B}$ in the packaging lines 1 to 5 , with lines 4 and 5 being part of the same double packaging line. These lines had different characteristics and usually produced different types and sizes of packages. However, changeover tasks were similar across all lines and if one would break down, one of the others could be adapted to replace it. The number of machines in lines $1,2,3$ and $4 / 5$ was respectively $5,10,9$ and 12 , while changeovers per month in the same lines were on average 19, 28, 22 and 35.

Unlike the previous case study, lean practices and tools were already known to company management and employees, namely SMED was applied to lines 8 and 9 with the help of external consultants. After one year it was observed that workers did not follow the standardized procedures, failing to achieve objectives. Faced with this, the company reviewed the implementation plan, main identified flaws were:

- lack of involvement of employees, only one worker per line was involved in the project, not allowing the rest to provide feedback or present ideas

- lack of monitoring, after the initial implementation the process was never reviewed and rarely checked to ensure it was being followed

- lack of a continuous improvement culture.

For the newer implementations, now reported, all workers were involved in the project and the used method was similar across all packaging lines, allowing employees being allocated to different lines if needed.

As historical data was considered scarce and unreliable a thorough analysis of the production system was performed. Firstly, operations performed by workers during changeovers were timed and video recorded, a spaghetti diagram was drawn to identify unnecessary movements, and a first set of corrective measures was thought out. Afterwards, operators received training concerning SMED, watched the changeover recordings, and were encouraged to discuss the tasks performed and how they could be improved. A changeover matrix was also produced and corrective measures defined. This was done for each work shift, allowing defining standards for changeover operations, for which all operators received training and encouraged to use. 


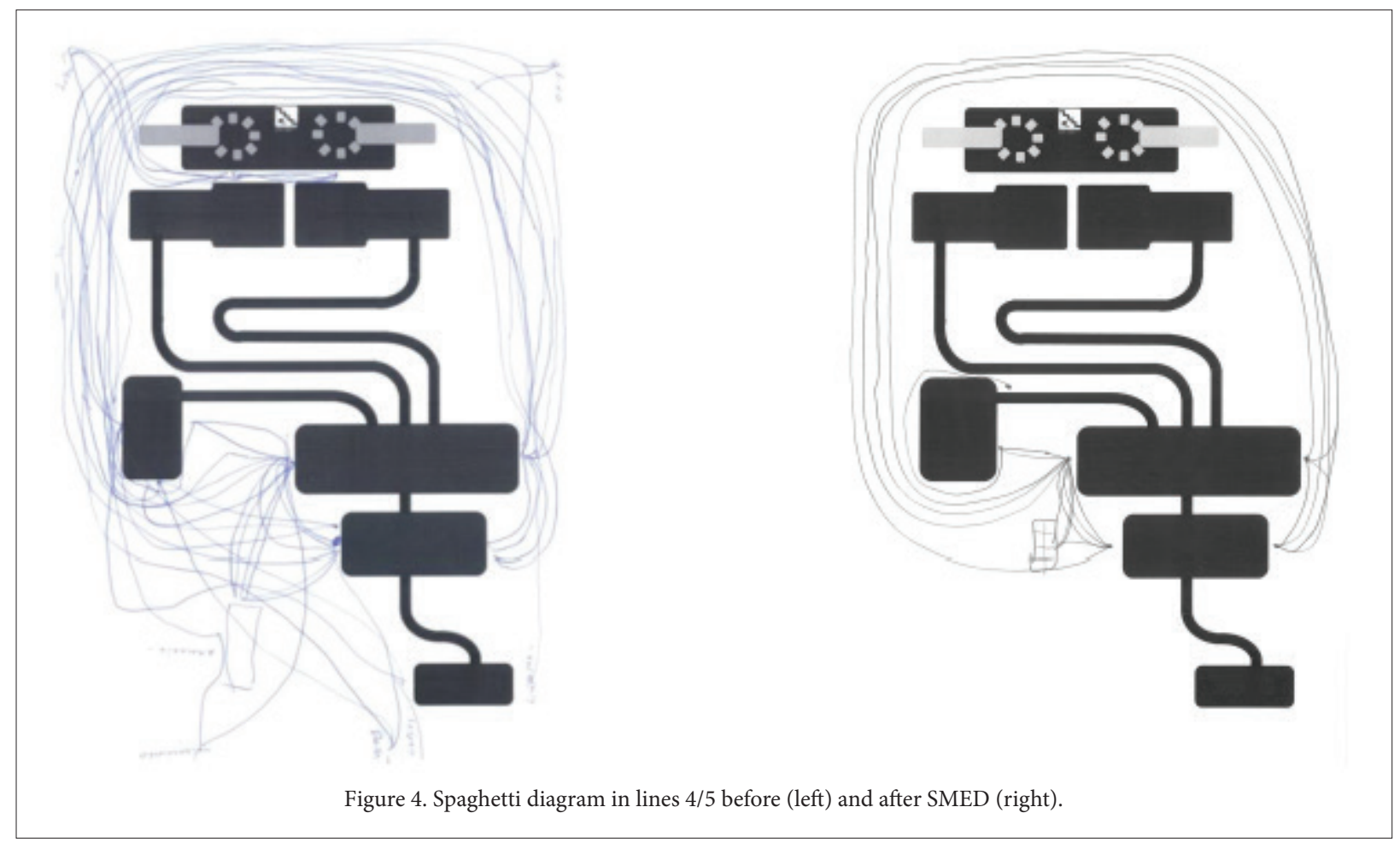

Once standards were defined, the SMED implementation according to Shingo (1985) ensued. The "separate" stage enabled classifying tasks as internal or external, grouped afterwards. In these changeovers run-down and run-up times were extremely short and therefore it was not found useful to differentiate them. Then, in the second stage, on average 8,11, 3 and 10 tasks respectively for lines 1 , 2, 3 and $4 / 5$ were converted into external. These were mostly tasks intending fetching/storing materials for performing the changeover, making small tests to the product, and cleaning the machine or the workspace. In "streamline", tasks were attempted improving by using dedicated movable workbenches and visual management for showing recommended actions. Additionally, there were some equipment design improvements on the packaging lines and on measurement tools, the latter being the one providing the largest time reductions.

Table 5 shows average values of number of tasks and changeover duration before and after SMED implementation, time reductions were in the range $23-45 \%$. A (conservative) estimate points to savings of 100.000 Euros/year just from this increase in productivity. SMED was applied in the following order: line 3 , lines $4 / 5$, line 2 , and line 1 . Interestingly, the success of the first implementation was already known in the following, to the point where operators were highly motivated into reaching the same level of success in their respective lines.

\begin{tabular}{|l|c|c|c|c|c|c|c|c|}
\cline { 2 - 9 } \multicolumn{1}{c|}{} & \multicolumn{2}{c|}{ Line 1 } & \multicolumn{2}{c|}{ Line 2 } & \multicolumn{2}{c|}{ Line 3 } & \multicolumn{2}{c|}{ Lines 4/5 } \\
\cline { 2 - 9 } \multicolumn{1}{c|}{} & \# Tasks & Time & \# Tasks & Time & \# Tasks & Time & \# Tasks & Time \\
\hline Before SMED & 25 & $00: 36: 40$ & 27 & $00: 46: 48$ & 30 & $00: 52: 43$ & 30 & $00: 43: 20$ \\
\hline $\begin{array}{l}\text { Total internal } \\
\text { after SMED }\end{array}$ & 17 & $00: 20: 00$ & 16 & $00: 27: 54$ & 27 & $00: 35: 00$ & 20 & $00: 33: 20$ \\
\hline Improvement & & $45.45 \%$ & & $40.38 \%$ & & $33.61 \%$ & & $23.08 \%$ \\
\hline
\end{tabular}

Table 5. Average number of tasks and times per changeover before and after SMED.

Based on past experience, it was considered important to perform regular audits on changeover operations for ensuring standardized work is adhered to. After several months audit results and collected data showed that changeover times were indeed reduced and best practices were still being followed. The difference considered having the biggest impact between these implementations and the ones performed previously in lines 8 and 9 (which failed to meet objectives) was that all employees were now part of the implementation team and their feedback and suggestions were highly valued. 


\section{Conclusions}

In the last decades lean has been a major catalyst for organizational and process innovation in manufacturing companies. Despite successful applications being reported in several industrial sectors, concerning food and beverage industries these have been lacking. The characteristics of these sectors may have led to resistance in changing companies' practices and embracing new management philosophies such as LM.

This work presents two case studies of companies of the food and beverage industries which have experienced successful LM applications. For the reported cases, several improvements could be found on implementing LM principles and tools, extending even beyond direct gains in productivity, e.g., improving production flexibility, increasing employee engagement, and motivating a continuous improvement culture. Based on these results, it can be concluded that this management philosophy can also be applied to these sectors making information in this paper of interest to general food and beverage manufacturers, particularly medium and large sized companies.

Moreover, this work reinforces employee engagement and empowerment as critical to the success of lean implementations. In one of the case studies it was considered the main driver, as was the main difference to a previously failed application of SMED. Therefore, even though technical aspects are relevant and drivers for an initial process innovation using lean tools (techniques used in the presented case studies seem to more easily identify issues and/or help solving them) for maintaining process innovations employee engagement is critical.

As future work, a follow up on the level of lean implementation and cultural change in the companies addressed in this study is advised. Also, specifically concerning SMED, future work may focus on more accurately quantifying the impact of machine design changes and the impact in inventory reduction. Finally, another interesting research avenue may be comparing LM implementation results among companies of different sectors. This would allow further understanding the potential and importance of process innovation in different industrial contexts.

\section{Acknowledgements}

This work was supported by Portuguese funds through the CIDMA - Center for Research and Development in Mathematics and Applications, and the Portuguese Foundation for Science and Technology ("FCT - Fundação para a Ciência e a Tecnologia"), within project PEst-OE/MAT/UI4106/2014.

\section{References}

Bayo-Moriones, A., Bello-Pintado, A., \& Cerio, J. M. D. (2010). 5S use in manufacturing plants: Contextual factors and impact on operating performance. International Journal of Quality \& Reliability Management, 27, 217-230. doi: 10.1108/02656711011014320
Boston Consulting Group (2015). Lean food-and-beverage manufacturing: Lower costs, better products, improved sustainability. Retrieved June 20, 2015, from http://www.bcg.com/documents/ file49085.pdf

Cakmakci, M. (2008). Process improvement: Performance analysis of the setup time reduction-SMED in the automobile industry. The International Journal of Advanced Manufacturing Technology, 41, 168179. doi: 10.1007/s00170-008-1434-4

Chapman, C. D. (2005). Clean house with lean 5S. Quality Progress, $38,27-32$.

Coimbra, E. A. (2009). Total flow management: Achieving excellence with kaizen and lean supply chains. Zug: Kaizen Institute.

Courtois, A., Martin-Bonnefous, C., \& Pillet, M. (2007). Gestão da produção: Para uma gestão industrial ágil, criativa e cooperante. Lisboa: Lidel.

Cox, A., \& Chicksand, D. (2005). The limits of lean management thinking: Multiple retailers and food and farming supply chains. European Management Journal, 23, 648-662. doi: 10.1016/j.emj.2005.10.010

Davenport, T. H. (1993). Process innovation: Reengineering work through information technology. Harvard Business Review Press.

Dennis, P. (2007). Lean production simplified. New York: Productivity Press.

Dora, M., Goubergen, D. V., Kumar, M., Molnar, A., \& Gellynck, X. (2014). Application of lean practices in small and medium-sized food enterprises. British Food Journal, 116, 125-141. doi: 10.1108/BFJ-052012-0107

Dudbridge, M. (2011). Handbook of lean manufacturing in the food industry. Chichester: Wiley-Blackwell.

Ferradás, P. G., \& Salonitis, K. (2013). Improving changeover time: A tailored SMED approach for welding cells. Procedia CIRP, 7, 598-603. doi: 10.1016/j.procir.2013.06.039

Gapp, R., Fisher, R., \& Kobayashi, K. (2008). Implementing 5S within a Japanese context: An integrated management system. Management Decision, 46, 565-579. doi: $10.1108 / 00251740810865067$

Gest, G., Culley, S. J., McIntosh, R. I., Mileham, A. R., \& Owen, G. W. (1995). Review of fast tool change systems. Computer Integrated Manufacturing Systems, 8, 205-210. doi: 10.1016/0951-5240(95)00011-H

George, M. L. (2003). Lean six sigma for service: How to use lean speed and six sigma quality to improve services and transactions. McGraw-Hill.

Henry, J. R. (2012). Achieving lean changeover: Putting SMED to work. Boca Raton, FL: Productivity Press. 
Heymans, B. (2015). Lean manufacturing and the food industry. Retrieved June 5, 2015, from http://www.flowmakers.com/articles/ Articlefoodindustryandkaizen.pdf

Hirano, H. (1996). 5 S for operators: 5 pillars of the visual workplace. Portland: Productivity Press.

Hirano, H. (2009). JIT implementation manual - The complete guide to just-in-time manufacturing: Volume 2 - Waste and the 5S's. New York: Productivity Press.

Hodge, G. L., Ross, K. G., Joines, J. A., \& Thoney, K. (2011). Adapting lean manufacturing principles to the textile industry. Production Planning \& Control, 22, 237-247. doi: 10.1080/09537287.2010.498577

Holden, R. J. (2011). Lean thinking in emergency departments: A critical review. Annals of Emergency Medicine, 57, 265-278. doi: 10.1016/j.annemergmed.2010.08.001

Kennedy, I., Plunkett, A., \& Haider, J. (2013). Implementation of lean principles in a food manufacturing company. In A. Azevedo (Ed.), Advances in Sustainable and Competitive Manufacturing Systems, Lecture Notes in Mechanical Engineering (pp. 1579-1590). Springer. doi: 10.1007/978-3-319-00557-7_127

Kumar, M., Antony, J., Singh, R. K., Tiwari, M. K., \& Perry, D. (2006). Implementing the lean sigma framework in an Indian SME: A case study. Production Planning \& Control, 17, 407-423. doi: 10.1080/09537280500483350

Mahalik, N. P., \& Nambiar, A. N. (2010). Trends in food packaging and manufacturing systems and technology. Trends in Food Science \& Technology, 21, 117-128. doi: 10.1016/j.tifs.2009.12.006

Marodin, G. A., \& Saurin, T. A. (2013). Implementing lean production systems: Research areas and opportunities for future studies. International Journal of Production Research, 51, 6663-6680. doi: 10.1080/00207543.2013.826831

McIntosh, R., Owen, G., Culley, S., \& Mileham, T. (2007). Changeover improvement: Reinterpreting Shingo's "SMED” methodology. IEEE Transactions on Engineering Management, 54, 98-111. doi: 10.1109/ TEM.2006.889070

Mika, G. (2006). Kaizen event implementation manual, 5th edition. Dearborn, MI: Society of Manufacturing Engineers.
Moreira, A. C., \& Pais, G. C. S. (2011). Single minute exchange of die. A case study implementation. Journal of Technology Management \& Innovation, 6, 129-146. doi: 10.4067/S0718-27242011000100011

OECD (2005). OSLO manual, guidelines for collecting and interpreting innovation data, 3rd Edition. OECD.

Patel, V. C., \& Thakkar, H. (2014). Review on implementation of 5S in various organization. International Journal of Engineering Research and Applications, 4, 774-779.

Pearce, A., \& Pons, D. (2013). Implementing lean practices: Managing the transformation risks. Journal of Industrial Engineering, 2013, 19 pages. doi: 10.1155/2013/790291

Shingo, S. (1985). A revolution in manufacturing: The SMED system. Cambridge, MA: Productivity Press.

Simons, D., \& Zokaei, K. (2005). Application of lean paradigm in red meat processing. British Food Journal, 107, 192-211. doi: 10.1108/00070700510589495

Sousa, R., \& Voss, C. A. (2008). Contingency research in operations management practices. Journal of Operations Management, 26, 697713. doi: 10.1016/j.jom.2008.06.001

Thun, J. H., \& Hoenig, D. (2011). An empirical analysis of supply chain risk management in the German automotive industry. International Journal of Production Economics, 131, 242-249. doi: 10.1016/j. ijpe.2009.10.010

Utterback, J. M., \& Abernathy, W. J. (1975). A dynamic model of process and product innovation. Omega, 3, 639-656. doi: 10.1016/03050483(75)90068-7

Vlajic, J. V., Vorst, J. G. A. J., \& Haijema, R. (2012). A framework for designing robust food supply chains. International Journal of Production Economics, 137, 176-189. doi: 10.1016/j.ijpe.2011.11.026

Womack, J. P., Jones, D. T., \& Ross, D. (1990). The machine that changed the world. London: Macmillan.

Yin, R. K. (2014). Case study research: Design and methods. Sage publications. 